\title{
Failure analysis of aluminum reinforced composite vessel
}

\begin{abstract}
At this paper attempts have been made to determine the effects of internal pressure on the reinforced composite pressure vessel. Finite element analysis (FEA) along with the Tsai-Wu failure criterion was utilized to predict the failure pressure of the vessel and the optimum fiber angle orientation. Six layers of E-glass/Epoxy and Graphite/Epoxyfibers have been selected to reinforce the aluminium vessel. Fibers were oriented with six different winding angles of 300, 450, 550, 600, 750 and 900 at asymmetric fiber orientation. The commercial code ABAQUS CAE was employed to simulate the model and analyse the structure. Results were revealed that Graphite/Epoxy has higher strength in comparison with E-glass/Epoxy fiber. Also it was observed that for both composite materials 550fiber angle is the optimum winding angle. Results were compared to the experimental ones and there was a good agreement between them.
\end{abstract}

Keyword: Composite vessel; Failure pressure; Fiber angle; Finite element analysis 